\title{
RISK OF CHRONIC DISEASES LIMITING LONGEVITY AND HEALTHY AGING BY LIFESTYLE AND SOCIO-ECONOMIC FACTORS DURING THE LIFE-COURSE - A NARRATIVE REVIEW
}

\author{
Dagmar Skýbová ${ }^{1,2}$, Hana Šlachtová ${ }^{1,2}$, Hana Tomášková1,2, Andrea Daleckál,2, Rastislav Madar ${ }^{1}$ \\ University of Ostrava, Ostrava, Czech Republic \\ Faculty of Medicine \\ ${ }^{1}$ Department of Epidemiology and Public Health \\ ${ }^{2}$ Centre for Epidemiological Research
}

\begin{abstract}
The review provides a comprehensive summary of existing literature focusing on the most serious risk factors of non-communicable diseases and collects current knowledge on their distribution, determinants, clusters, psychological and socio-economic consequences. Especially, the life-course approach is stressed, early life consequences of the later onset of chronic diseases, the risk behavior and its social, socio-economic and psychosocial determination is reviewed. Potential of preventing these harmful consequences has a lifelong approach. The aim is to demonstrate the opportunity for future health system transformation in terms of public health prevention regarding the non-communicable diseases. It is concluded that personalized lifestyle medicine should address a patient's health by empowering them with the information they need to regain control of their health. Preventive methods should be tailored for each patient, considering such patient's specific genes, environment, lifestyle, early life factors and social patterns of risk factors to avoid burden of health in later age. Intervention and preventive measures should target not only to individual factors but should reflect wider social, psychosocial and socio-economic consequences. It is also crucial from the point of view of public health to consider data on exposome, which are not included in epidemiological studies as well as its impact on health in the context of non-communicable diseases. Med Pr. 2021;72(5):535-48
\end{abstract}

Key words: risk factors, psychosocial determinants, non-communicable disease, life-course perspective, social health inequalities, clusters of risks

Corresponding author: Dagmar Skýbová, University of Ostrava, Faculty of Medicine, Department of Epidemiology and Public Health, Centre for Epidemiological Research, Syllabova 19, 70300 Ostrava - Vítkovice, Czech Republic, e-mail: dagmar.skybova@osu.cz

Received: April 8, 2021, accepted: September 2, 2021

\section{INTRODUCTION}

The health of the individual and the population is affected by many factors. In the past, communicable infectious diseases have predominated, but in recent decades there has been a shift and predomination of lifestylerelated chronic diseases. Chronic non-communicable diseases (NCDs) represent serious health problem and are the leading cause of death in the world. Latest data presenting by WHO in 2016, showed that $71 \%$ (57 million) of deaths are caused by NCDs, in total 15 million of them were premature (in age group 30-70 years) [1], deaths from NCDs are projected to rise. The main NCDs include cardiovascular diseases (CVD), type II diabetes, cancer and respiratory diseases. Together, they account for $77 \%$ of the disease burden and almost $86 \%$ of premature mortality [2]. Despite the fact that the risk of premature death of NCDs decreased when comparing data from 2000 to 2016 (decrease of 19\% in women and $18 \%$ in men), NCDs still represent the most challenging cause of death which requires a response from policy makers [3].

Funding: this work was funded by the student grant project from the Faculty of Medicine at the University of Ostrava (Project No. SGS06/LF/2021 entitled "Lifestyle factors determining healthy aging," project manager: Hana Šlachtová) and supported by the European Union (Project No. CZ.02.1.01/0.0/0.0/16_019/0000798 entitled "Healthy Aging in Industrial Environment HAIE," project manager: Radim Srám). 
Non-communicable diseases are characterized by their behavior in terms of long duration, slow progress and results of combination various factors - genetic, physiological, environmental, socio-economic and behavioral substantially influencing human's lifestyle (occupational and living conditions, leisure-time physical activity, stress, entertainment, unhealthy diet, traveling, communication, consumer behavior, etc.). They also have an effect on psychological health, influence social engagement, social roles, challenges intellectual resources in understanding and disease management.

There are several risk factors typical for young generation which contribute to burden of disease in the short-time and also relate to morbidity and mortality later in adulthood [4]. These, mostly behavioral, risk factors include alcohol consumption, illicit drug use and unprotected sex. Numerous cohort studies demonstrate that the risk behavior as well as lifestyle indicators evolved in adolescence are associated with expansion of later NCDs, such as cancer, heart diseases and type II diabetes.

We have been processing and analysing a cohort of data from a long-term study related to parents of children that lasted more than 25 years. This narrative overview was prepared to obtain an overview and evaluation of the results so far achieved and the state of knowledge in this area, which will be used as a background for the discussion of the study results. The aim of which is to demonstrate a life-course-depended risk factors influencing the onset of disease later in life. The reason is summarization of available information regarding the onset of risk behavior in life course and its consequences on development of the first chronic disease.

We focus on modifiable risk factors such as smoking, unhealthy diet, physical activity, harmful use of alcohol, psychosocial determinants of risk behaviors, individual differences (by sex, age), life-course perspective, clustering of risk factors.

This review provides a comprehensive summary of the very current existing literature on the impact of social, psychological and socio-economic consequences on leading risk factors contributing to major NCDs.

\section{METHODS}

The database PubMed and Google Scholar were searched for relevant studies together with WHO latest relevant publications focusing on selected specific topics since 2015 to April, 2020 using the following key words: diet, food intake, healthy diet, risk behavior, behaviors, smoking, smoking onset, BMI (body mass index), physical activity, sedentary lifestyle, alcohol consumption, drinking patterns, addiction, life-course perspective, psychosocial determinants, socioe-conomic status, ses, social health inequalities, individual health risk factors, age, aging, age onset and sex, in combination with chronic non-communicable disease, NCD. Studies in languages other than English were excluded.

Results of databases searching were complemented by latest adequate publications and position papers on specific interesting topics from the WHO website.

The inclusion criteria were as follows:

case-control or cohort-based study design;

- systematic reviews and meta-analysis;

publication date of the paper later in time from the date of WHO publication.

The exclusion criteria were as follows: abstracts without full texts.

\section{RESULTS}

\section{Risk factors}

Chronic non-communicable diseases risk factors can be summarized into 2 basic categories. These are metabolic (raised blood pressure, overweight, obesity, high level of glucose or plasma concentrations of lipoproteins in blood) and behavioral risk factors which are modifiable.

\section{Tobacco use}

Smoking is a leading cause of cancer ( $>20$ different types or subtypes of cancer), CVD and respiratory system along with many other debilitating health conditions [5]. Onset and persistence of smoking are influenced by genetic and environmental factors [6]. Middle adolescence is a period when many starts smoking and the influence of a shared environment can have an important influence [7]. From the environmental factors, parental smoking has been well-documented as a predisposing factor of smoking initiation in offspring. Consistent evidence on the effects of genetics on smoking and nicotine addiction has been provided by studies on twins, family and adoption [7]. It is important to note that early age of smoking initiation is associated with greater daily cigarette consumption and reduction the likelihood of quitting [8].

An important threat to public health is the tobacco epidemic, which kills 7 million people each year as a result of direct tobacco use. It is estimated that 1.2 million deaths of non-smokers are related to exposure to second-hand smoke [9] in other words each year 65000 children die 
due to illnesses related to second-hand smoking [5]. In terms of prevalence, higher prevalence was observed in disadvantaged groups whose smokers may face higher risk [10]. The trend in tobacco use is declining worldwide for both sex in all income groups and is expected to continue.

A constant decrease of smokers is a major public health success. Nevertheless, we can still observe a very high number of tobacco users worldwide (globally 1.3 billion in 2018) [11]. Public health and epidemiology have a decisive role in providing evidence related to improvement of the public health and subsequent reduction of inequalities.

\section{Unhealthy diet}

Unhealthy diet and insufficient physical activity are the leading global health risks as dietary factors are the crucial components in order to undermine health and well-being. Diet is a modifiable behavior with the potential to mitigate chronic disease risk. Systematic evaluation of the impact of suboptimal diet as a preventive factor on the ballast of NCD has not been evaluated [12].

Impaired diet quality, composition and excessive food intake, together with a lack of physical activity, usually results in overweight and obesity, the prevalence of which in the range of 2000-2016 was even higher than overweight [13]. Although obesity can be prevented by a combination of social change and personal choice, constantly dietary risks cause 11 million deaths globally in 2017. In adults under the age of 70, the leading cause of diet-related death was cardiovascular disease, followed by cancer and type II diabetes [12].

The association between dietary habits and NCDs has been investigated in many studies. However, not many researches have been considered dietary habits in relation to life expectancy without disease. Major part of studies is focused on linking food intake to chronic disease but there is no well-established link between dietary quality and self-assessment with dietary behavior and related health outcomes. An alternative index of healthy nutrition or recommended dietary recommendations, which are based on long questionnaires on the frequency of diet, are often used to assess the quality of nutrition. Unfortunately, the current evidence of food environments and diet are inconsistent, possibly by reason of heterogeneity in methods used to the evaluation of diet [14]. As the results of the inconsistent methodology, there is geographically unrepresentative data on food consumption, imperfectly described distribution of dietary intake of the population, bias in the evaluation of diet from various sources, the use of standardized intake to 2000 calories per day without considering differences between persons and influencing factors [12].

\section{Physical activity}

Physical inactivity is recognized as a global pandemic. The level of physical activity (PA) that is recommended is not met worldwide in the order of 1.4 billion adults [15]. It is estimated that more than 1.3 million deaths worldwide would be prevented if there were a 25\% decrease in the prevalence of insufficient PA [16].

The level of physical inactivity is increasing with economic development of countries. There are countries that show up 70\% of PA as a result of developing arrangement of transportation, elevated use of technology and urbanization [17].

According to the results of epidemiological studies, people with low levels of PA have an approx. 35\% higher risk of all causes mortality than people with high levels of PA [18]. People are spending more and more time sedentary behaviors and that is recognized to be associated with all causes mortality as well as mortality for diseases of cardiovascular system, type II diabetes and cancer [17].

Regularity of PA is a demonstrably well-established and well-functioning protective factor acting as a prevention or treatment of NCDs like heart disease, stroke, type II diabetes, breast and colon cancer. It also plays a role in preventing the symptoms of the metabolic syndrome (hypertension, overweight, obesity), improving mental health, slowing the onset of dementia, Alzheimer's disease and, last but not least, improving the quality of life and well-being [17].

Data on PA are not always comparable in epidemiological studies and it is difficult to compare their results. Different studies use diverse assessment methods and methodology. Some surveys refer leisure, transport, occupational (or school) and household while others to total PA (including work and travelling) as well as leisure activities such as sport. The difference is also in data receiving - questionnaire or accelerometer-assessed PA. Accelerometers are primarily used in small studies, but they allow PA to be objectively quantified and evaluated on the different levels although they have their limits (higher costs, lack of contextual information). Comparison of questionnaire research is limited by the group of respondents for whom the questionnaires are intended (age category, health condition etc.) categorization of questions type related to PA. 
Questionnaires filled in by respondents bring self-reports, but their shortcoming is distortion in the form of social desire and recall of feedback bias. Currently, there is no harmonization and standardization of measurement and evaluation methods.

\section{Harmful use of alcohol}

At present, there is no set dose of alcohol consumption that could be guaranteed as safe or risk-free. Alcoholic beverages are classified by International Agency for Research on Cancer (IARC) as human carcinogen, Group 1 with no known safe level of minimum drinking which means that regular drinking increases risk of cancer rise.

Alcohol as one of the risk factors of NCDs has a very complex and multidimensional relationship from its consumption to health consequences. Alcohol consumption is affected by individual risk factors (gender, age, socio-economic status (SES)) and environmental factors (availability of alcohol, the economic status of a country). Equally important is the genetic predisposition that affects alcohol abuse, early onset of drinking, stress-related drinking and the development of addiction [19].

More than 200 diseases can be caused by harmful alcohol use (both chronic and acute) and can cause injury conditions (both unintentional and intentional). Adolescents are a sensitive group as harmful drinking can cause health problems in later life and affect life expectancy. Among other things, reduces their self-control and thus at the same time increases risky behavior.

Alcohol-related consequences, in terms of NCD, can be associated with malignant neoplasms, disorders in alcohol use, alcohol poisonings, fetal alcohol syndrome, epilepsy and other neuropsychiatric disorders such as hazardous drinking increase the risk of depression [20]; extreme binge drinking and heavy consumption of alcohol lead to higher cognitive decline in men, diseases of the digestive tract and others. However, there are exceptions such as ischemic heart diseases and diabetes, with curvilineal relationships, and with benefits of light to moderate drinking in people without heavy irregular drinking episodes [21]. The cohort study published by Park [22] dealing with the cessation of alcohol consumption in relationship with health effects came up with interesting results. CVD or other NCDs were not significant in terms of onset and treatment of the disease, but cessation of alcohol consumption in cancer patients confirmed a significant effect on both the onset of the disease and the treatment itself [22].

Consumption of alcohol is also associated with a number of the infectious disease related to sexually transmitted diseases and also has an indirect impact on HIV/AIDS mortality due to the increased risk of unprotected sex [23].

Epidemiological studies address the measurement of alcohol exposure in different ways for example measurement of average volume consumption received from questionnaires or simple measures of frequency and quantity [21], irregular heavy drinking occasions. The problem is that most studies do not include changes over time and detect alcohol consumption only once and moreover only at the beginning of research (chronic or irregular heavy drinking). Another problem is the inconsistency and underreporting (not contentive in demographic or consumer groups) of alcohol consumption in population surveys using standardized frequency questions. Quantity, frequency and average drinking volume multiplied by frequency does not provide information about drinking patterns. Drinking patterns may also characterize the association between alcohol consumption and dietary intake in terms of more relevant to NCDs outcomes than average volume.

\section{Psychosocial determinants of risk behaviors}

Health inequalities by socio-economic position are substantial. It is considered that people with a higher socioeconomic position are often the first to abandon behaviors that are found to damage health such as smoking, high-fat diets, behaviors promoting health [24].

\section{Socio-economic status, social health inequalities}

Socio-economic status has been recognized as important health determinant that might influence the people's approaches, experiences and exposure to factors that influences heath during the course of life. The research points out that socio-economically disadvantaged environments plays an important role during childhood, because it is subsequently associated with unfavourable results in adulthood. Likewise, it is well-documented that those who have low SES possess worse health across many SES indicators and measures of health [25]. Socioeconomic status determines the risk and vulnerability of individuals to risk factors of NCDs, which emphasizes the effort to examine the prevalence of risk factors along SES categories. NCDs are more frequent in disadvantaged and marginalized people and communities than 
in groups with higher SES [26]. The higher risk of unhealthy lifestyle has children growing up in households with lower SES.

The conclusions of research work following up the social inequalities in health confirms the lower prevalence of health issues, illness, diseases, and death in people with higher SES [27].

Inequalities in SES among others, affect smoking, which significantly contributes to morbidity and mortality, especially premature ones. Smoking behaviors and their related disease risks are socially patterned and positively associated with health inequalities. Smokers, ex-smokers, never smokers and second-hand smokers exposed to environmental tobacco smoke are at risk of many chronic diseases. Studies show that only a few people understand the concrete health risks associated with tobacco use. However, when smokers realize the dangers of tobacco, most of them want to quit [9]. Low SES is associated with a higher prevalence of smoking, slower progress in reducing smoking prevalence [28], significantly higher prevalence of tobacco and alcohol consumption, earlier outset of smoking, less successful quitting, frequent experience of adverse health effects, and premature death than affluent groups with high SES [29]. Household expenses is thus diverted from basic needs to risk behavior, which strengthen the poverty [9]. Low SES also interacts with a complex array of other factors to influence smoking behavior like cultural characteristics, social marginalization, stress, influence of tobacco industry, insufficient comprehensive tobacco control policy [28].

Smoking addiction and tobacco dependence are related to social deprivation; therefore, smoking rates are especially high among the long term unemployed, homeless, mentally ill, prisoners and single parents [10].

Some research papers suggest that smoking leads to greater health inequalities more than social status alone and contributes to socio-economic inequalities in health more than alcohol, PA, or dietary patterns. This offers area for prevention and is also the reason for past successes.

Systematic review of de Ridder et al. [30] pointed out non-compliance with a healthy diet has the only consistent risk factor, which is low SES. The effect of individual SES indicators (for example lower education and less valuable occupation) contributes to differences in eating habits and their effect can be cumulative [31]. Socio-economically disadvantaged groups are the least likely to consider recommendations on eating habits when buying food, and as a result they have a higher risk of developing diet-related diseases [32].
The source of nutrients is therefore a fundamental difference that we observe among social classes. A special place is occupied by the high intake of fats in diet, which is observed in all social groups. Healthy eating and quality diets are associated with greater abundance, while energy-rich diets, which are poor in nutrients, are consumed by persons with lower SES and limited economic resources [33]. The most vulnerable group in the population in terms of their ability to eat healthy are low-income people. These are mainly young families, the elderly and the unemployed [14]. Notwithstanding recommendations diet quality follows a socio-economic gradient and can be explained by diet cost [33]. The social gradient in quality of diet contributes to health inequalities [14].

High SES is associated with higher levels of PA which is one of the most important behaviors explaining higher mortality in population with lower SES [34]. The literature discusses the influence of sedentary behavior and environmental conditions in terms of unsafe neighbourhood, low walkability, aesthetics. Various environments - such as physical and social (economic conditions, societal norms, urbanization, industrialization) - are often assumed by ecological models as significant determinants of PA [35]. Global Health Observatory data from Europe (2016) showed that the prevalence of insufficient PA among adults (aged $>18$ years) is in both sexes $29.4 \%$ (26.2\% males and $32.4 \%$ female). Globally for both sexes $27.5 \%$ (23.4\% male and $31.7 \%$ female) - over the past 15 years, levels of insufficient PA did not intensify (28.5\% in 2001 ; $27.5 \%$ in 2016) [36].

The consequences of alcohol consumption are diverse - from harmful effect on health to death. The overall consumption of alcohol tends to increase with SES but alcohol attribute deaths is elevated in lower SES groups [37]. Studies showed that deprived drinkers were more likely to smoke, be overweight and report poor diet and exercise [38]. Alcohol consumption reduces labour productivity and can lead to undesirable labor market outcomes both in the short (absence from work) and in the long term (health complications). The psychosocial consequences of alcohol consumption are also significant (breakdown of family, relationships, friendship, crimes, violence, neglect and abuse of children, reduction of overall productivity) [37].

Social inequity in health can only arise from variations or differences in health due to a combination of 3 differentiating traits. They are systematic, socially produced (and therefore modifiable) and unfair [39]. 
A more detailed understanding of the demographic and socio-economic model of multimorbidity and risk factors distribution would help to target the prevention activities to the most vulnerable groups.

\section{Individual risk differences}

\section{Health differences by sex}

Among men and women, there are biological differences which cause the major reasons for variation in the risk of death from NCDs (cancers of reproduction organs - cervical, breast; prostate and testicular cancer). Well confirmed difference between men and women is an unhealthy lifestyle, risk behaviors, less tendency to use health services, visit a doctor less frequently (norms of masculinity; other socio-economic factors of men). The risks of premature NCD death decreased (from 2000 to 2016) and the relative declines were smaller for men than for women [3].

Chronic non-communicable diseases indicators reveal differences in sex among socio-economic groups and across the life-course (health outcomes, exposure to main risks, acceptation of healthy behaviors, access of services, responses from providers, usage of care). Studies also show that countries with lower income inequality have specifics positively affecting health. For example, we can observe that boys living in these countries tend to have lower mortality rates, fewer psychological and physical symptoms, lower BMIs, are more physically active, have higher self-reported health, and have a low prevalence of bullying. There is a growing number of obese children in Europe, especially boys (social gradient, with higher rates among the most disadvantaged groups) [40].

There are also disparities between the sexes in PA - for example women are more likely to have insufficient PA (31.7\% vs. $23.4 \%$ of men) [3]. Several research work in this area point to lower PA in women than in men as well as still rising in high-income countries [15]. Defiance of the importance and benefits of PA in the management of NCDs, women do not change it in their lives even after diagnosis. Women have more often financial limitation, lack of decision-making power, the additional workload in the household, which subsequently then worsens the allocation of adequate resources and time for PA [3]. The individual factors like age, sex, health status, selfefficacy, prior PA are consistent correlates of PA [35].

Gender is one of the most influential factors in smoking habits that has been recognized. The risks associated with long-term smoking in women are higher and women have even more risks associated with tobacco use (breast and cervical cancer). The worldwide average decrease in the prevalence of tobacco use is observed both for men (a decrease of 11.4\% between 2000 and 2018) and for women (a decrease of $8.2 \%$ between 2000 and 2018). The tobacco use is four times lower in women than in men [41].

Gender differences in relation to the alcohol as a risk factor are more common in high-income countries, where we observe significant differences in alcohol use disorders between sex in the European Region (men $14.8 \%$ and women $3.5 \%$ in 2016). Mortality due to the effects of alcohol consumption is greater than the effects of diabetes (2.8\%), tuberculosis (2.3\%), HIV/AIDS (1.8\%) and high blood pressure (1.6\%) [23]. Alcohol is the cause of $6.1 \%$ of cancer deaths in the EU+ region (by gender, the distribution of men is $8 \%$ and women $3.6 \%$ ) [23].

\section{Health differences by age}

The burden of disease in the population has generally shifted. In adults, there has been a shift from infectious to chronic diseases. In children (0-18 years), we observe a shift from infants and children to new-borns and adolescents. The prevalence of sick adolescent lifestyle also varies between age groups. In general, older people tend to be sicker than younger ones, due to the natural aging process. During the period of growth and development of children, especially up to 3 years of age and to a certain extent also in adolescence, may occur particularly significant effects as a result of various exposures (inadequate nutrition, pollutants, infections, adverse conditions in social or psychosocial area) [39]. The issue of multimorbidity in terms of age was researched and the results showed that multimorbidity is common in middle-aged people, where its prevalence increased with age from almost $30 \%$ in the 45 49 age group to $52 \%$ in the $60-64$ age group [42]. This indicate that multimorbidity is common in people $>65$ years of age. Most of the chronic conditions are preventable and could be avoided through the adoption of healthy lifestyle recommendations (regular exercise, healthy eating, normal BMI, avoiding smoking and excessive alcohol consumption) [6]. Healthy lifestyle results in decreasing the risk of developing NCDs [43] which commonly come up in middle age after long exposure to an unhealthy lifestyle affected by unhealthy behaviors like lack of regular PA, unhealthy diet, tobacco and alcohol use, stress exposure [43].

Most of the studies report a statistically significant negative association of smoking with healthy ageing (current smoking proved a strong harmful impact on health compared to non-smoking). Environmental 
factors, in other words mutual and family influences as the strongest contributors in determining how and when cigarette experiments take place among young people [39]. World Health Organization indicates that tobacco use usually begins in adolescence and $10 \%$ of 13-15-year-olds worldwide are smokers [44]. A minority of studies report that never-smoking and lower tobacco consumption are positively associated with healthy ageing. Quitting smoking pays off (the rule is the sooner the better), because it brings with it the benefit of prolonging life at any age. The results of the research show that people who have stopped smoking for a long time will have a greater impact on their health in proportion to the number of years since smoking cessation. Those who quit smoking, reduce the risk to their health, particularly if they quit in middle age [45].

Various dietary components have been described to influence risk factors and the prevalence of age-related disease outcomes. One of the most important factors influencing the burden of premature morbidity and mortality is poor and unhealthy nutrition. Represents more than $10 \%$ of disability-adjusted life years (DALYs) chiefly from CVD and diabetes [46]. Increasing presence of overweight, obesity and diet related NCDs in children and adults are chiefly in urban populations ( 1 in 3 people is directly affected by underweight, vitamin and mineral deficiency, overweight, obesity, etc.). The result is premature mortality and the early onset of disease with high level of disability [47].

The health benefits of PA, beneficial effects on NCDs, brain health, psychological health, and quality of life are well known by both the public and the health care, but just a small amount of the people meets the recommendations of PA. Health promotion programs should target people of all ages and focus on reasons of inactivity since the risk of NCDs begins in childhood and increases with age. The crude estimate of global prevalence data of insufficient PA among school-going adolescents (aged $11-17$ years) is $81.0 \%$ for both sexes (male $77.6 \%$, female 84.7\%) in 2016 and for Europe WHO reports $82.1 \%$ in both sexes (male $77.5 \%$, female $87.0 \%$ ) [36]. In addition, PA is associated with reduced mortality from all causes [48], good health in old age as well as to cognitive performance. Insufficient PA results in an increased risk of many adverse health conditions, including major NCDs (cardiovascular disease, diabetes and various types of cancer, shortens life expectancy and increases the risk of premature mortality [49]. The aging process can be affected by the level of PA, although the specific relationship to healthy aging is not yet clear.
Many secondary effects of PA are beneficial on health, for instance plasmatic levels of inflammatory markers that result in reducing of cardiovascular risk, psychosocial development of both young and old, contribution in delaying brain ageing and degenerative pathologies and many others.

Another risk factor of NCDs is the consumption of alcohol during life. Substantial concern relates to early initiation of alcohol consumption since the first experience of alcohol before the age of 15 years was associated with 4 times higher probability to being diagnosed for alcohol dependency in adulthood [50]. These findings were reported in several independent cohorts. Adults who experienced long-term unemployment before the age of 33 in all probability, report risk health behaviors than those who had no such experience, including those from more advantaged backgrounds. Alcohol also affects employment. Unemployment for more than 3 years significantly predicts heavy drinking in young men and a higher frequency of drinking in men aged 27-35 [51]. Even among people aged 20-39, the highest proportion of all deaths is caused by alcohol consumption $(13.5 \%)$ [23].

\section{Life-course perspective}

Risks for an onset of NCDs accumulate throughout life. Potential in prevention has a life course approach from before conception through fetal life, all developmental stages of child, adulthood and into old age. The greatest potential to influence NCDs early in life is preventing environmental exposures and occupational health risks during pregnancy and childhood. The risk of disease across the life-course is modified by the health behaviors that people adopt. Child and adolescent public health have a unique added value as a base of life course approach to health of population. Childhood and adolescence are the stages of life in which this behavior is created [52] (parents influence their children's diets and eating habits and at the same time their PA) and if created properly, they promote health and protect against the development of NCDs throughout life. A major public health problem in Europe is the ever-increasing incidence of childhood obesity, as there is a possibility that these children will become adults with the same weight problems. From a gender perspective, boys are more at risk than girls and there is a clear social gradient with a higher rate of the most disadvantaged groups [40].

Anyway, adolescents have been considered as the most important group of the population for the direction of prevention and building the sustainable lifestyle 


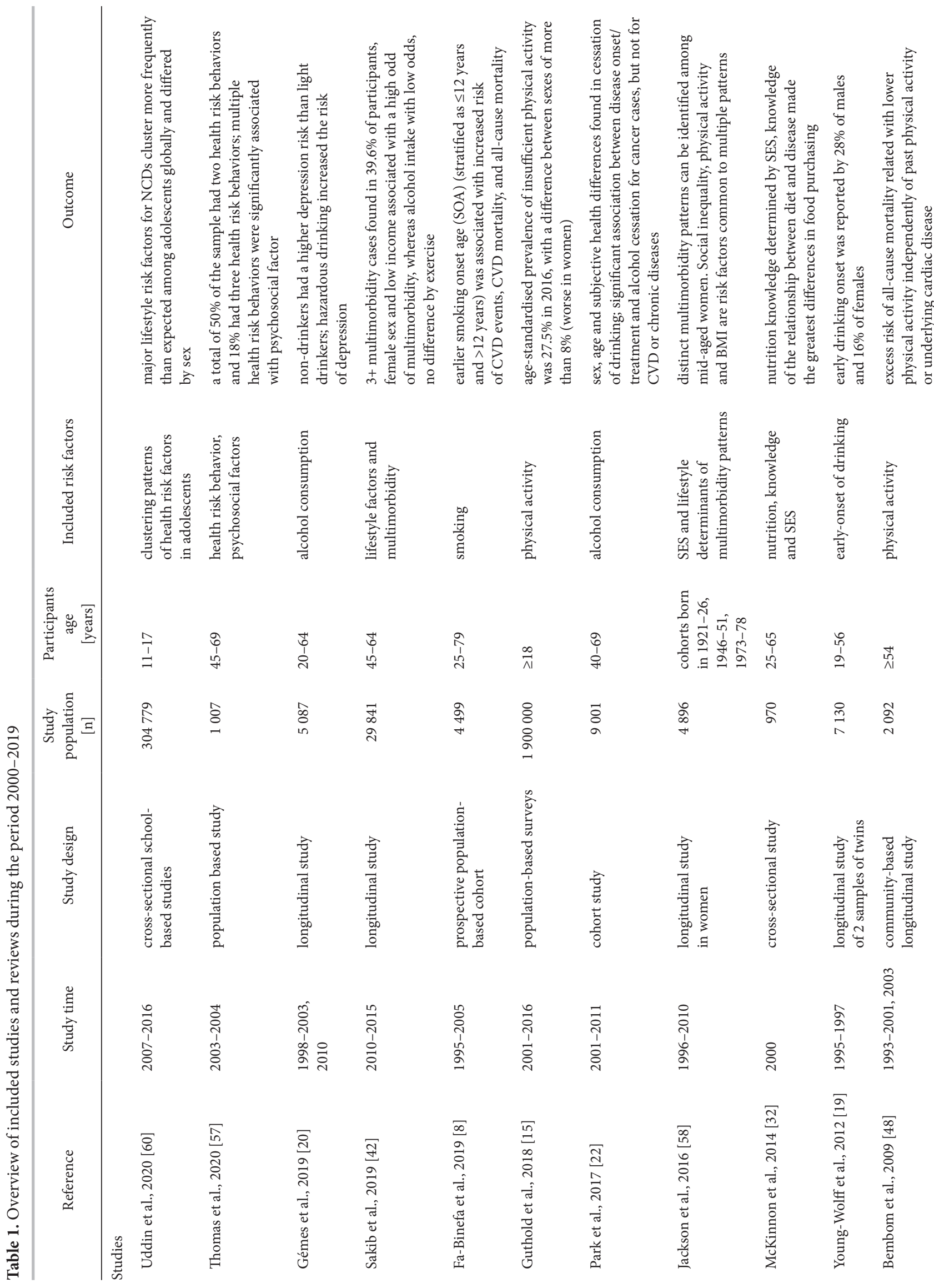



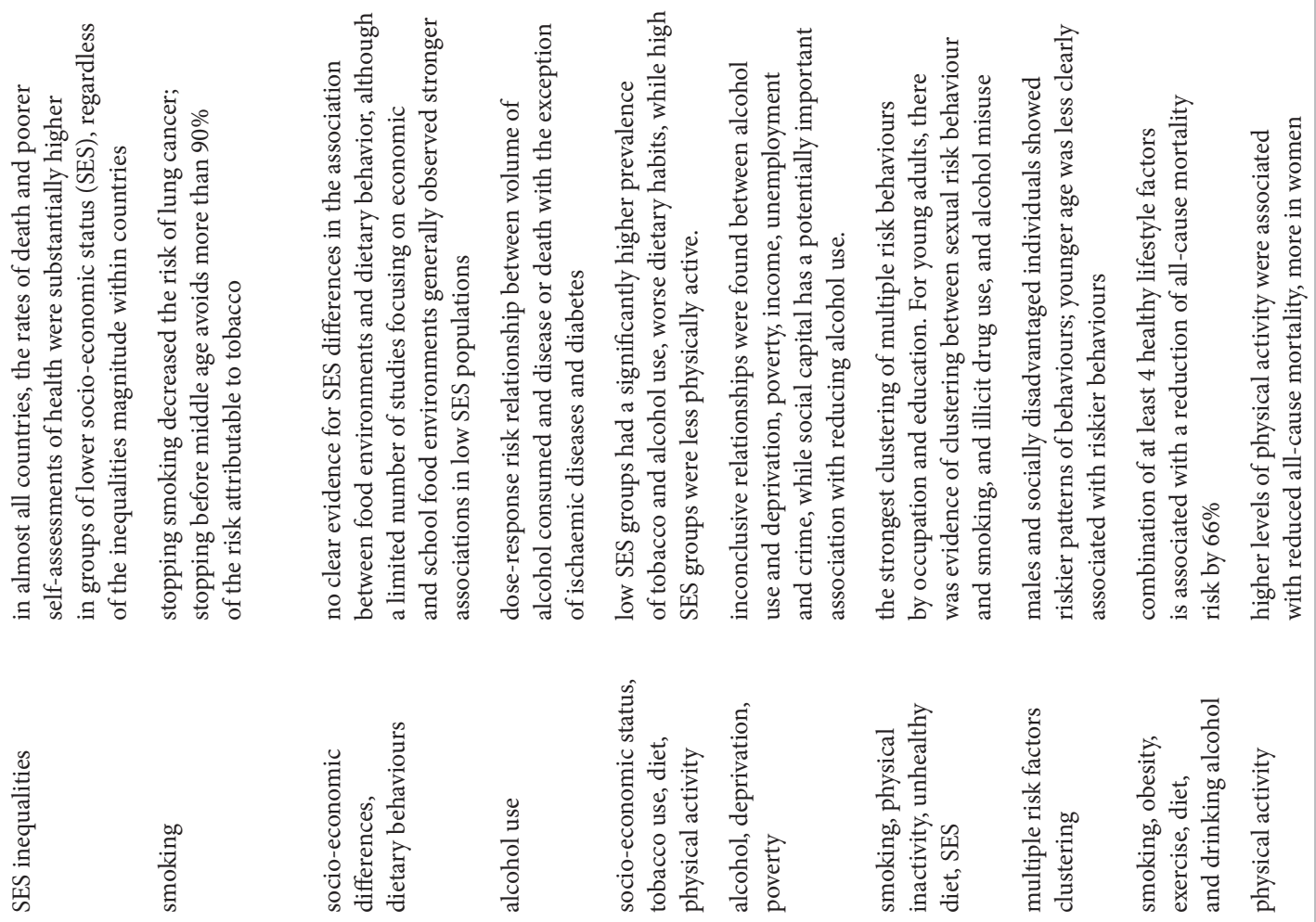

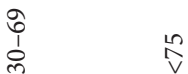

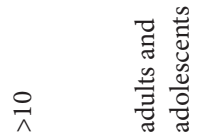<smiles>[13CH3]</smiles>

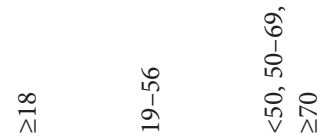

$\begin{array}{ll}8 & \text { है } \\ 0 & \text { in } \\ 0 & 0\end{array}$

$\underset{\substack{m \\ m}}{\stackrel{2}{2}}$

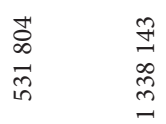<smiles>CC1[C@H](C)C[C@H]1C</smiles>

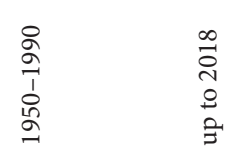

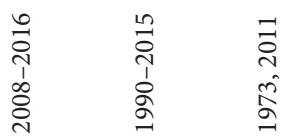

0
$\stackrel{1}{1}$
$\vdots$
$\vdots$

m

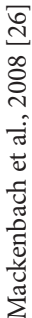

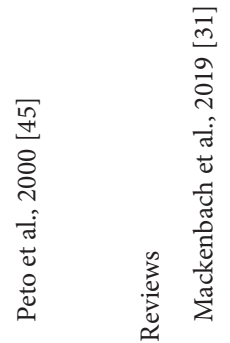

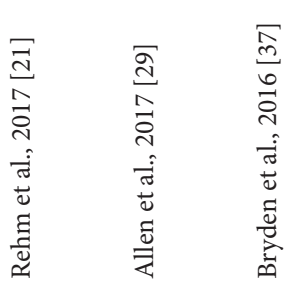

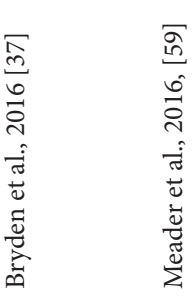

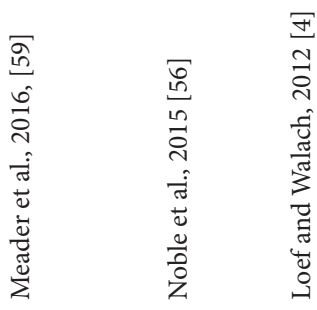

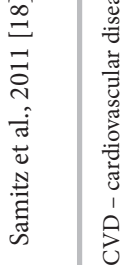


that reduce subsequent disease burden in adulthood. It is a period that is prone to adopt unhealthy lifestyle behaviors and forming key health-related behaviors, posing risks to current and future NCD loads. Adolescents with longer participation in education, less health risk, and slower transitions to marriage and parenthood generally gain greater abilities and resources for health [53]. Supporting or, conversely, compromising the health and well-being of adolescents has consequences during their lifetime and also affects the healthy beginning to life of the next generation. Conversely, adolescent health problems and health risks reduce fitness and lifetime health. There are many risk factors which can influence the health of adolescent (sexual health risks, the risk for infectious diseases, tobacco and alcohol use, greater sedentary behavior and diminished PA, mental disorders, etc.). The immediate health consequences, addiction and acceleration of NCDs over a lifetime is a result of youth and young people's smoking. Particularly pronounced in mid-adolescence may be the impact of shared environment when many begin smoking [7]. Nevertheless, adolescence is mostly marked as the healthiest part of life. This is a time of peak health, because from the point of view of health services, adolescents have fewer needs than those in early childhood or later years.

Behavioral lifestyle factors are particularly important to public health as they are a modifiable and important component in health improvement. Adulthood is the period in which the greatest build up in risks occurs, however they begin to accumulate earlier [52]. Most people who use tobacco today have started in adolescence age.

This is exceptionally important in the context of research conclusion of that healthy behaviors, healthy lifestyle and thought patterns in middle age can lead to healthy aging. Middle age (the transition between early and late adulthood) is a period of decreasing physical functions and increasing stress as a result of family and work responsibilities. Such conditions can cause health problems among middle age adults, and it is therefore important to develop or maintain good health behavior in this population group. It was found that in the 7 th and 8th decades of life, behavior, mindset, emotional and spiritual lifestyle in middle age have a greater impact than expected [54].

Consuming a healthy diet throughout the life-course helps to prevent the number of NCDs (e.g., diabetes, heart disease, stroke and cancer). Diabetes has 1 in 12 adults worldwide. This is mainly type II diabetes, which is often undiagnosed [47]. Nutrition is a modifiable factor which appears to be a strong element of improvement of quality of life and many ageing processes. Last but not least, it should be mentioned that in food preferences among older adults are environmental factors more significant than genetic ones [6].

There are opinions in the literature that the presence of NCDs in older people is clearly not related to healthy ageing. The reason is that most respondents suffer from a certain disease and are in some way accustomed to the difficulties associated with it (problem can be more visible when it influences daily activities, due to pain presence or psychological disorders). The period of transition from work to retirement is a great opportunity to plan health promotion interventions. People are looking for resources and ways how to spend their free time. Clustering in terms of the probability that an individual with one chronic disease will have other chronic conditions is high - many older adults have $\geq 2$ chronic conditions at the same time [55].

The development and expansion of measures to optimize the growth and development of body composition, the maintenance of physical and cognitive functions in childhood and adolescence helps to better understand the mechanisms underlying the associations between early life and later disease [52].

\section{Clustering of risk factors}

The clustering of risk factors and behavior of individuals is confirmed by many studies. Adults often engage in $\geq 2$ risky behaviors at once [56] and this clustering is then more commonly observed in low socio-economic groups (income and education) [57]. Risk factors common to multiple patterns are social inequality, physical activity and BMI [58]. This points to need focus on prevention targeting on multiple risk behaviors. Clustering of risk behaviors increases the risk of NCDs. Clustering of risk factors in relation to health is an area of research in which more and more evidence is being identified, but unfortunately there is little consensus on which risk factors should be clustered and for which subgroups of people [56]. A systematic review of Meader et al. [59] came with almost strong evidence of clustering in adult populations between alcohol misuse and smoking; and unhealthy diet and smoking. Occupations (up to 4-times increased odds in lower SES groups) and education (up to 5-times increased odds in those with no qualifications) show the strongest associations with the occurrence and clustering of multiple risky behaviors. The most common risky behavior clustering in the adult 
population is alcohol misuse and smoking (cluster even together) [59]. This combination is highly comorbid and poses a multiplicative health risk when used together [59]. During adolescence period behavioral risk factors (physical inactivity, poor diet, alcohol and tobacco abuse) predominate and often clustering. Not much is known about prevalence and distribution of the co-occurrence of these factors in adolescents. The study of Uddin et al. [60] has analysed global data of 304779 adolescents aged 11-17 years focused on clustering of lifestyle risk factors. The results showed that the most common single lifestyle risk factor for NCDs was the low fruit-vegetable intake. Globally and regionally, regardless of gender, they have emerged as the most clustering multiple risk lifestyle factors, cigarette smoking and alcohol consumption [60]. Protective factors tend to cluster together too. This can be explained on fact that individuals who focus on one healthy behavior will engage in other healthy behavior (exercise, healthy diet, enough sleep) further.

The studies and reviews used for review are presented in Table 1 (study time, study design, study population, participants age, included risk factors, outcome).

\section{CONCLUSIONS}

Based on the current literature review, there is a number of potential confounders that affect the development of NCDs risk factors from the early life through the adolescent to the old age, which often cluster according to the socio-economic and psychosocial factors. Health inequalities are socially patterned and socially determined and belong among the most serious predictors of burden of disease.

Intervention and preventive measures should target not only by factors but should be focused on reflecting wider social, psychosocial and socio-economic consequences. A newly developed term "personalized lifestyle medicine" may provide a new perspective how to influence or address a patient's health by providing information that will help regain control of their health and to improve individual health outcomes regarding chronic diseases. A personalized approach in preventive methods and treatments for each patient should be formed and prioritized with respect to specific genes, lifestyle and environment. Diversification, rapid population aging and chronic diseases are a significant concern of individuals, families, society and health care systems. Lifestyle medicine could be basic guide for success of efforts focused on prevention and control of NCDs, improving health of the population and elimination of health disparities.

From a public health point of view understanding the consequences of non-communicable diseases over the life course is a topic which is not sufficiently explored and has not received sufficient attention in longitudinal studies. Most studies focus on specific age groups and risk factors and due to this, data on the contextual factors of NCDs formation and the development of risk factors are lacking.

It is crucial to consider data on exposome which are missing as the sum of all lifetime exposures and their impact on health in context of susceptibility to NCDs. There is a lack of links between non-chemical stressors, environmental pollution, social relations and socio-economic factors, which are also involved in the prevalence.

Thus, the currently available data do not sufficiently capture the complexity of the relationship between the environment, health and differences at the population level. This is probably due to the complexity of collecting (highly variable exposure, dynamic throughout life, its impact varies depending on the life stage of the individual) and evaluating this data. Establishing cohorts, preferably new-borns, for long-term monitoring and evaluation would be an ideal solution to advance research in this area especially in the field of chronic diseases in which non-genetic factors outweigh hereditary factors.

\section{REFERENCES}

1. World Health Organization [Internet]. Geneva: The Organization; 2020 [cited 2020 May 5]. Noncommunicable diseases country profiles 2018. Available from: https://www. who.int/nmh/publications/ncd-profiles-2018/en/.

2. World Health Organization [Internet]. Geneva: The Organization; 2020 [cited 2020 Apr 22]. European food and nutrition action plan 2015-2020. Available from: http:// www.euro.who.int/__data/assets/pdf_file/0003/294474/ European-Food-Nutrition-Action-Plan-20152020-en.pdf.

3. World Health Organization [Internet]. Geneva: The Organization; 2019 [cited 2020 June 14]. World health statistics 2019: monitoring health for the SDGs, sustainable development goals. Available from: https://apps.who.int/iris/bit stream/handle/10665/324835/9789241565707-eng.pdf?se quence $=9$ \&isAllowed $=\mathrm{y}$.

4. Loef M, Walach $\mathrm{H}$. The combined effects of healthy lifestyle behaviors on all cause mortality: a systematic review and meta-analysis. Prev Med. 2012;55(3):163-170, https://doi. org/10.1016/j.ypmed.2012.06.017. 
5. World Health Organization [Internet]. Geneva: The Organization; 2020 [cited 2020 June 10]. Health topics Tobacco. 29 April 2020. Available from: https://www.who. int/health-topics/tobacco\#tab=tab_1.

6. Fisher EB, Fitzgibbon ML, Glasgow RE, Haire-Joshu D, Hayman LL, Kaplan RM, et al. Behavior matters. Am J Prev Med. 2011;40(5):e15-e30, https://doi.org/10.1016/ j.amepre.2010.12.031.

7. Sullivan PF, Kendler KS. The genetic epidemiology of smoking. Nicotine Tob Res. 1999;1 Suppl 2:S51-S70. https://doi.org/10.1080/14622299050011811.

8. Fa-Binefa M, Clará A, Pérez-Fernández S, Grau M, Dégano IR, Marti-Lluch R, Ramos R, et al. Early smoking-onset age and risk of cardiovascular disease and mortality. Prev Med. 2019 Jul;124:17-22, https://doi.org/10. 1016/j.ypmed.2019.04.022.

9. World Health Organization [Internet]. Geneva: The Organization; 2020 [cited 2020 July 6]. Fact sheets. Key facts. Tobacco. 27 May 2020. Available from: https://www. who.int/news-room/fact-sheets/detail/tobacco.

10. Hiscock R, Bauld L, Amos A, Fidler JA, Munafò M. Socioeconomic status and smoking: a review. Ann N Y Acad Sci. 2012;1248:107-123, https://doi.org/10.1111/ j.1749-6632.2011.06202.x.

11. Marmot M. Social justice, epidemiology and health inequalities. Eur J Epidemiol. 2017 Jul;32(7):537-546, https://doi.org/10.1007/s10654-017-0286-3.

12. GBD Diet Collaborators. Health effects of dietary risks in 195 countries, 1990-2017: a systematic analysis for the Global Burden of Disease Study 2017. Lancet. 2019; 393(10184):1958-1972, https://doi.org/10.1016/S0140-6736 (19)30041-8

13. FAO, IFAD, UNICEF, WFP and World Health Organization [Internet]; Rome, 2019 [cited 2020 July 14]. The State of Food Security and Nutrition in the World 2019. Safeguarding against economic slowdowns and downturns. Available from: https://www.who.int/nutrition/pu blications/foodsecurity/state-food-security-nutrition2019-en.pdf?ua=1.

14. Kirkpatrick SI, Reedy J, Butler EN, Dodd KW, Subar AF, Thompson FE, et al. Dietary assessment in food environment research: a systematic review. Am J Prev Med. 2014; 46(1):94-102, https://doi.org/10.1016/j.amepre.2013.08.015.

15. Guthold R, Stevens GA, Riley LM, Bull FC. Worldwide trends in insufficient physic activity from 2001 to 2016: a pooled analysis of 358 population-based surveys with 1.9 million participants [published correction appears in Lancet Glob Health. 2019 Jan;7(1):e36]. Lancet Glob Health. 2018;6(10):e1077-e1086, https://doi.org/10.1016/ S2214-109X(18)30357-7.
16. Bray F, Soerjomataram I. The Changing Global Burden of Cancer: Transitions in Human Development and Implications for Cancer Prevention and Control. In: Gelband H, Jha P, Sankaranarayanan R, Horton S, eds. Cancer: Disease Control Priorities, Third Edition (Volume 3). Washington (DC): The International Bank for Reconstruction and Development / The World Bank; 2015 Nov 1. Chapter 2. Available from: https://www.ncbi. nlm.nih.gov/books/NBK343643/.

17. World Health Organization [Internet]. Geneva: The Organization; 2018 [cited 2020 July 17]. Global action plan on physical activity 2018-2030: more active people for a healthier world. Available from: https://apps.who.int/ iris/bitstream/handle/10665/272722/9789241514187 -eng.pdf.

18. Samitz G, Egger M, Zwahlen M. Domains of physical activity and all-cause mortality: systematic review and doseresponse meta-analysis of cohort studies. Int J Epidemiol. 2011;40(5):1382-1400. https://doi.org/10.1093/ije/dyr112.

19. Young-Wolff KC, Kendler KS, Prescott CA. Shared genetic contributions to early-onset drinking and drinking to cope motives. Addict Behav. 2012;37(10):1176-1180, https://doi.org/10.1016/j.addbeh.2012.05.009.

20. Gémes K, Forsell Y, Janszky I, László KD, Lundin A, Ponce De Leon A, et al. Moderate alcohol consumption and depression - a longitudinal population-based study in Sweden. Acta Psychiatr Scand. 2019;139(6):526-535, https://doi.org/10.1111/acps.13034.

21. Rehm J, Gmel GE Sr, Gmel G, Hasan OSM, Imtiaz S, Popova $\mathrm{S}$, et al. The relationship between different dimensions of alcohol use and the burden of disease-an update. Addiction. 2017;112(6):968-1001, https://doi.org/10.1111/ add.13757.

22. Park JE, Ryu Y, Cho SI. The Association Between Health Changes and Cessation of Alcohol Consumption. Alcohol. 2017 May 1;52(3):344-350, https://doi.org/10.1093/alcalc/ agw089.

23. World Health Organization [Internet]. Geneva: The Organization; 2018 [cited 2020 July 1]. Alcohol. Available from: https://www.who.int/health-topics/alcohol\#tab=tab_1.

24. Mackenbach JP. The persistence of health inequalities in modern welfare states; the role of health behaviours. Euro Observer -Vol.20 |No.2 |2014 p. 6-9. [cited 2020 July 15]. Available from: https://apps.who.int/iris/bitstream/han dle/10665/332842/Eurohealth-20-2-2014-eng.pdf?sequ ence $=1$ \&isAllowed $=y$.

25. Ross CE, Mirowsky J. Neighborhood Socioeconomic Status and Health: Context or Composition? City \& Community, 7: 163-179, https://doi.org/10.1111/j.1540-6040. 2008.00251.x. 
26. Mackenbach JP, Stirbu I, Roskam AJ, Schaap MM, Menvielle G, Leinsalu M, et al. Socioeconomic inequalities in health in 22 European countries [published correction appears in N Engl J Med. 2008 Sep 18;359(12):e14]. $\mathrm{N}$ Engl J Med. 2008;358(23):2468-2481 https://doi. org/10.1056/NEJMsa0707519.

27. Marmot M, Allen JJ. Social Determinants of Health Equity. American Journal of Public Health 104, S517S519, https://doi.org/10.2105/AJPH.2014.302200.

28. Garrett BE, Dube SR, Babb S, McAfee T. Addressing the Social Determinants of Health to Reduce TobaccoRelated Disparities. Nicotine Tob Res. 2015;17(8):892-897, https://doi.org/10.1093/ntr/ntu266.

29. Allen L, Williams J, Townsend N, Mikkelsen B, Roberts N, Foster C, et al. Socioeconomic status and non-communicable disease behavioural risk factors in low-income and lower-middle-income countries: a systematic review. Lancet Glob Health. 2017;5(3):e277-e289, https://doi.org/ 10.1016/S2214-109X(17)30058-X.

30. de Ridder D, Kroese F, Evers C, Adriaanse M, Gillebaart M. Healthy diet: Health impact, prevalence, correlates, and interventions. Psychol Health. 2017;32(8):907-941, https:// doi.org/10.1080/08870446.2017.1316849.

31. Mackenbach JD, Nelissen KGM, Dijkstra SC, Poelman MP, Daams JG, Leijssen JB, et al. A Systematic Review on Socioeconomic Differences in the Association between the Food Environment and Dietary Behaviors. Nutrients. 2019;11(9):2215. Published 2019 Sep 13, https://doi.org/ 10.3390/nu11092215.

32. McKinnon L, Giskes K, Turrell G. The contribution of three components of nutrition knowledge to socio-economic differences in food purchasing choices. Public Health Nutr. 2014;17(8):1814-1824, https://doi. org/10.1017/S1368980013002036.

33. Darmon N, Drewnowski A. Does social class predict diet quality? Am J Clin Nutr. 2008;87(5):1107-1117, https:// doi.org/10.1093/ajcn/87.5.1107.

34. Hankonen N, Heino MT, Kujala E, Hynynen ST, Absetz P, Araújo-Soares V, et al. What explains the socioeconomic status gap activity? Educational differences in determinants of physic activity and screentime. BMC Public Health. 2017;17(1):144. Published 2017 Feb 1, https://doi. org/10.1186/s12889-016-3880-5.

35. Bauman AE, Reis RS, Sallis JF, Wells JC, Loos RJ, Martin BW. Lancet Physical Activity Series Working Group. Correlates of physical activity: why are some people physically active and others not? Lancet. 2012;380(9838):258-271, https:// doi.org/10.1016/S0140-6736(12)60735-1.

36. World Health Organization [Internet]. Geneva: The Organization; 2020 [cited 2020 July 1]. Global Health
Observatory data repository - Insufficient physical activity. Available from: https://apps.who.int/gho/data/node. main.A892?lang=en.

37. Bryden A, Roberts B, Petticrew M, McKee M. A systematic review of the influence of community level social factors on alcohol use. Health Place. 2013;21:70-85, https:// doi.org/10.1016/j.healthplace.2013.01.012.

38. Bellis MA, Hughes K, Nicholls J, Sheron N, Gilmore I, Jones L. The alcohol harm paradox: using a national survey to explore how alcohol may disproportionately impact health in deprived individuals. BMC Public Health. 2016;16:111. Published 2016 Feb 18, https://doi.org/10. 1186/s12889-016-2766-x.

39. Whitehead M, Dahlgren G, World Health Organization [Internet]. Regional Office for Europe; 2006 [cited 2020 Apr 7]. Levelling up (part 1): a discussion paper on concepts and principles for tackling social inequities in health / by Margaret Whitehead and Göran Dahlgren. Available from: https://apps.who.int/iris/handle/10665/107790.

40. Hernández-Quevedo C, Gauci CH, Rechel B. [Internet]. Childhood obesity in Europen obesity polices to address it. Eurohealth- Vol.25| No.1| 2019 p. 7-10. [cited 2020 May 11]. Available from: https://apps.who.int/iris/bitstre am/handle/10665/332531/Eurohealth-25-1-2019-eng. pdf? sequence $=1$ \&isAllowed $=y$.

41. World Health Organization [Internet]. Geneva: The Organization; 2019 [cited 2020 Mar 3]. WHO global report on trends in prevalence of tobacco use 2000-2025, third edition. Available from: https://www.who.int./publi cations-detail/who-global-report-on-trends-in-prevalen ce-of-tobacco-use-2000-2025-third-edition.

42. Sakib MN, Shooshtari S, St John P, Menec V. The prevalence of multimorbidity and associations with lifestyle factors among middle-aged Canadians: an analysis of Canadian Longitudinal Study on Aging data. BMC Public Health. 2019;19(1):243. Published 2019 Feb 28, https:// doi.org/10.1186/s12889-019-6567-x.

43. Prasad S, Sung B, Aggarwal BB. Age-associated chronic diseases require age-old medicine: role of chronic inflammation. Prev Med. 2012;54 Suppl(Suppl):S29-S37. https://doi.org/10.1016/j.ypmed.2011.11.011.

44. World Health Organization [Internet]. Geneva: The Organization; 2015 [cited 2020 Mar 22]. WHO states that alcohol use begins in adolescence and that $25 \%$ of $13-15$ year olds report having an alcoholic drink within the past month in many countries. Healthy diet, fact sheet no. 394. Available from: http://www.who.int/nutrition/publications/nutrientrequirements/healthydiet_factsheet394.pdf.

45. Peto R, Darby S, Deo H, Silcocks P, Whitley E, Doll R. Smoking, smoking cessation, and lung cancer in the UK 
since 1950: combination of national statistics with two case-control studies. BMJ. 2000;321(7257):323-329, https:// doi.org/10.1136/bmj.321.7257.323.

46. Sievenpiper JL, Riccardi G, Ricordi C, Dembska K. Health and Dietary Trends. In: Editors, Achieving the Sustainable Development Goals Through Sustainable Food Systems. Springer, 2019, p. 63-82.

47. World Health Organization [Internet]. Geneva: The Organization; 2018 [cited 2020 July 2]. Global nutrition policy review 2016-2017: country progress in creating enabling policy environments for promoting healthy diets and nutrition. Available from: https://www.who.int/publi cations-detail/9789241514873.

48. Bembom O, van der Laan M, Haight T, Tager I. Leisuretime physical activity and all-cause mortality in an elderly cohort. Epidemiology. 2009;20(3):424-430, https://doi. org/10.1097/EDE.0b013e31819e3f28.

49. Ekelund U, Dalene KE, Tarp J, Lee IM. Physical activity and mortality: what is the dose response and how big is the effect? [published online ahead of print, 2020 Jan 21]. Br J Sports Med. 2020;bjsports-2019-101765, https://doi. org/10.1136/bjsports-2019-101765.

50. Grant BF, Dawson DA. Age of onset of drug use and its association with DSM-IV drug abuse and dependence: results from the National Longitudinal Alcohol Epidemiologic Survey. J Subst Abuse. 1998;10(2):163-173, https://doi.org/10.1016/s0899-3289(99)80131-x.

51. World Health Organization [Internet]. Geneva: The Organization; 2019 [cited 2020 July 7]. Evidence and resources to act on health inequities, social determinants and meet the SDGs. Available from: http://www.euro.who.int/ data/assets/pdf_file/0009/397899/20190218-h1740-sdgresource-pack-2.pdf?ua $=1$.

52. Baird J, Jacob C, Barker M, Fall CH, Hanson M, Harvey NC, et al. Developmental Origins of Health and Disease: A Lifecourse Approach to the Prevention of NonCommunicable Diseases. Healthcare (Basel). 2017;5(1): 14. Published 2017 Mar 8, https://doi.org/10.3390/health care5010014.
53. Patton GC, Sawyer SM, Santelli JS, Ross DA, Afifi R, Allen NB, et al. Our future: a Lancet commission on adolescent health and wellbeing. Lancet. 2016 Jun 11;387(10036): 2423-78, https://doi.org/10.1016/S0140-6736(16)00579-1.

54. Hartman-Stein PE, Potkanowicz ES. Behavioral determinants of healthy aging: good news for the baby boomer generation. Online J Issues Nurs. 2003;8(2):6.

55. Wolff JL, Starfield B, Anderson G. Prevalence, expenditures, and complications of multiple chronic conditions in the elderly. Arch Intern Med. 2002;162(20):2269-2276, https://doi.org/10.1001/archinte.162.20.226.

56. Noble N, Paul C, Turon H, Oldmeadow C. Which modifiable health risk behaviours are related? A systematic review of the clustering of Smoking, Nutrition, Alcohol and Physic activity, health risk factors. Prev Med. 2015;81:16-41, https://doi.org/10.1016/j.ypmed.2015.07.003.

57. Thomas K, Nilsson E, Festin K, Henriksson P, Lowén M, Löf $\mathrm{M}$, et al. Associations of Psychosocial Factors with Multiple Health Behaviors: A Population-Based Study of Middle-Aged Men and Women. Int J Environ Res Public Health. 2020;17(4):1239. Published 2020 Feb 14, https:// doi.org/10.3390/ijerph17041239.

58. Jackson CA, Dobson AJ, Tooth LR, Mishra GD. Lifestyle and Socioeconomic Determinants of Multimorbidity Patterns among Mid-Aged Women: A Longitudinal Study. PloS One. 2016;11(6):e0156804. Published 2016 Jun 3, https://doi.org/10.1371/journal.pone.0156804.

59. Meader N, King K, Moe-Byrne T, Wright K, Graham H, Petticrew $\mathrm{M}$, et al. A systematic review on the clustering and co-occurrence of multiple risk behaviours. BMC Public Health. 2016;16:657. Published 2016 Jul 29, https:// doi.org/10.1186/s12889-016-3373-6.

60. Uddin R, Lee EY, Khan SR, Tremblay MS, Khan A. Clustering of lifestyle risk factors for non-communicable diseases in 304,779 adolescents from 89 countries: A global perspective. Prev Med. 2020;131:105955, https:// doi.org/10.1016/j.ypmed.2019.105955.

This work is available in Open Access model and licensed under a Creative Commons Attribution-NonCommercial 3.0 Poland License - http://creativecommons.org/licenses/by-nc/3.0/pl/deed.en. 